\title{
Prospective cohort studies on risk factors for cardiovascular events in systemic lupus erythematosus: a major challenge
}

\author{
Irene EM Bultink* \\ See related research by Gustafsson et al., http://arthritis-research.com/content/11/6/R186
}

\begin{abstract}
Cardiovascular disease (CVD) has been identified as a major contributor to morbidity and mortality in patients with systemic lupus erythematosus (SLE). The etiology of premature CVD in SLE is supposed to have many factors, including traditional coronary artery disease (CAD) risk factors, antiphospholipid antibodies, and metabolic and inflammatory factors. Despite the overwhelming interest in CVD in SLE research, prospective studies evaluating risk factors for hard endpoints (that is, cardiovascular events) are relatively scarce. The article by Gustafsson and colleagues suggests that prothrombotic factors play an important role in SLE-related CVD and that the influence of traditional CAD risk factors might be limited.
\end{abstract}

In a recent issue of Arthritis Research \& Therapy, Gustafsson and colleagues [1] presented the results of an interesting prospective study on risk factors for cardiovascular events (CVEs) in 182 Swedish patients with systemic lupus erythematosus (SLE) who were selected to be free of CVEs at inclusion. In contrast to the numerous cross-sectional studies and research on surrogate markers of cardiovascular disease (CVD) performed, relatively few prospective studies on predictors of CVEs in SLE have been published [2-4]. In the present study, age, presence of any antiphospholipid antibody (aPL), von Willebrand factor (vWf), and absence of thrombocytopenia were independent predictors of the first CVE.

*Correspondence: iem.bultink@vumc.nl

Department of Rheumatology, VU University Medical Center, PO Box 7057, 1007 MB Amsterdam, The Netherlands
The study demonstrates the difficulties inherent in research of events in which the relative risk of the occurrence is high while the absolute risk of the event is low. Despite the improved overall survival in patients with SLE over the last decades, the risk for cardiovascular death has not diminished [5]. In female patients with SLE, the risk of myocardial infarction and stroke is 8- to 10 -fold greater than that of age-matched healthy women [6], and therefore the detection of predictors of these complications is of great importance. However, against the low background rate of CVEs in healthy, relatively young females, the absolute incidence rate of CVEs in lupus cohorts composed predominantly of females will be low. Gustafsson and colleagues report that 24 out of 182 patients with SLE (mean age of 44 years; $90 \%$ of the patients were female) had at least one CVE after a mean follow-up of 8 years; this equates to the occurrence of one first CVE in 63 patient-years. In the Lumina cohort, 34 out of 546 patients developed at least one CVE after a median follow-up of 6 years (one first CVE in 96 patientyears) [2], and in the Toronto cohort, 118 out of 1,087 patients had at least one arterial vascular event after an average follow-up of 9 years (one first event in 83 patientyears) [4]. These small absolute incidence rates illustrate the challenge of examining predictors of CVEs in SLE.

Another interesting issue is the association found between prothrombotic factors and endothelial activation and the occurrence of CVEs: vWf and the presence of any aPL were independent predictors of future CVEs in the Swedish patients with SLE [1]. As a marker of endothelial activation which promotes platelet adhesion and aggregation, vWf has been recognized as a predictor of cardiac events in other patient groups with preexisting vascular disease [7]. Moreover, increased vWf activity has been detected in SLE patients with subclinical atherosclerosis [8]. Release of vWf from endothelial cells can be induced by inflammatory cytokines [7] but might also be triggered by immunologic factors, as suggested by Gustafsson and colleagues. Indeed, IgG from 
thrombosis-susceptible patients with SLE has been demonstrated to induce the release of vWf [9], and in vitro, induction of vWf release by antibodies to doublestranded DNA has been shown [10].

Remarkably, although several markers of systemic inflammation (among others, high-sensitivity C-reactive protein) and markers of endothelial activation (vWf and soluble vascular cell adhesion molecule 1) were elevated at baseline in SLE patients who developed CVEs as compared with patients without CVEs, only the presence of $\mathrm{vWf}$ remained a significant predictor in multivariable regression analysis [1]. In contrast, C-reactive protein serum levels at baseline predicted vascular events in the Lumina cohort [2].

The presence of any aPL at baseline as a predictor of future vascular events has been reported from the Hopkins cohort [11] and the Lumina cohort [2] and is confirmed by the Swedish study [1]. The possible protective role of thrombocytopenia with respect to the occurrence of future CVEs, as reported by Gustafsson and colleagues, is a novel and interesting observation but this finding needs to be confirmed in other studies. As discussed by the authors, the lack of association of traditional coronary artery disease risk factors, except age, might be explained by the limited number of patients and events in the study [1].

Another limitation of the present study might be the racial and ethnic background of the study population. The great majority of the patients (94\%) were Caucasians of European origin. Since racial and ethnic background influences disease severity and organ damage in patients with SLE, confirmation of the results of the Swedish study in SLE cohorts with a significantly different racial and ethnic background in other parts of the world will be of great interest.

Despite more than three decades of research on the pathogenesis of CVD in SLE, the exact risk factors and the relative contribution of and interplay between thrombotic, atherosclerotic, and inflammatory factors are still under debate, and this hampers the development of intervention strategies to prevent CVEs in patients with SLE. Large-scale prospective studies performed by collaborating SLE research groups are needed to answer these important questions and to develop new intervention strategies based on measures that have been proven effective in the prevention of SLE-related CVD. The next challenge will be the implementation of these prevention strategies in routine clinical practice.

\section{Abbreviations}

aPL, antiphospholipid antibody; CVD, cardiovascular disease; CVE cardiovascular event; SLE, systemic lupus erythematosus; vWf, von Willebrand factor.

\section{Competing interests}

The author declares that she has no competing interests.

Published: 22 February 2010

\section{References}

1. Gustafsson J, Gunnarsson I, Börjesson O, Petterson S, Möller S, Guo-Zhong F, Elvin K, Simard JF, Hansson L-O, Lundberg IE, Larsson A, Svenungsson E: Predictors of the first cardiovascular event in patients with systemic lupus erythematosus - a prospective cohort study. Arthritis Res Ther 2009, 11:R186.

2. Toloza SM, Uribe AG, McGwin G Jr., Alarcón GS, Fessler BJ, Bastian HM, Vilá LM, Wu R, Shoenfeld Y, Roseman JM, Reveille JD, for the LUMINA Study Group: Systemic lupus erythematosus in a multiethnic US cohort (LUMINA). XXIII. Baseline predictors of vascular events. Arthritis Rheum 2004, 50:3947-3957.

3. Mok CC, Tang SS, To CH, Petri M: Incidence and risk factors of thromboembolism in systemic lupus erythematosus. A comparison of three ethnic groups. Arthritis Rheum 2005, 52:2774-2782.

4. Urowitz MB, Ibanez D, Gladman DD: Atherosclerotic vascular events in a single large lupus cohort: Prevalence and risk factors. J Rheumato/ 2007, 34:70-75.

5. Bernatsky S, Boivin JF, Joseph L, Manzi S, Ginzler E, Gladman DD, Urowitz M, Fortin PR, Petri M, Barr S, Gordon C, Bae S-C, Isenberg D, Zoma A, Aranow C, Dooley M-A, Nived O, Sturfelt G, Steinsson K, Alarcón G, Senécal J-L, Zummer M, Hanly J, Ensworth S, Pope J, Edworthy S, Rahman A, Sibley J, El-Gabalawy $\mathrm{H}, \mathrm{McC}$ arthy T, et al:. Mortality in systemic lupus erythematosus. Arthritis Rheum 2006, 54:2550-2557.

6. Esdaile JM, Abrahamowicz M, Grodzicky T, Li Y, Panaritis C, du Berger R, Côté R, Grover SA, Fortin PR, Clarke A, Senécal J-L: Traditional Framingham risk factors fail to fully account for accelerated atherosclerosis in systemic lupus erythematosus. Arthritis Rheum 2001, 44:2331-2337.

7. Spiel AO, Gilbert JC, Jilma B: Von Willebrand factor in cardiovascular disease: focus on acute coronary syndromes. Circulation 2008, 117:1449-1459.

8. de Leeuw K, Freire B, Smit AJ, Bootsma H, Kallenberg CG, Bijl M: Traditional and non-traditional risk factors contribute to the development of accelerated atherosclerosis in patients with systemic lupus erythematosus. Lupus 2006, 15:675-682.

9. Lindsey NJ, Dawson RA, Henderson Fl, Greaves M, Hughes P: Stimulation of von Willebrand factor antigen release by immunoglobulin from thrombosis prone patients with systemic lupus erythematosus and the anti-phospholipid syndrome. Br J Rheumatol 1993, 32:123-126.

10. Lai KN, Leung JCK, Lai KB, Lai FM, Wong KC: Increased release of von Willebrand factor antigen from endothelial cells by anti-DNA autoantibodies. Ann Rheum Dis 1996, 55:57-62.

11. Petri $\mathrm{M}$ : The lupus anticoagulant is a risk factor for myocardial infarction (but not atherosclerosis): Hopkins Lupus Cohort. Thromb Res 2004, 114:593-595

doi:10.1186/ar2927

Cite this article as: Bultink IEM: Prospective cohort studies on risk factors for cardiovascular events in systemic lupus erythematosus: a major challenge. Arthritis Research \& Therapy 2010, 12:107. 